\title{
ANÁLISE DA ESTRATÉGIA INICIAL DE INTERNACIONALIZAÇÃO: ESTUDO MULTICASOS DE EMPRESAS EXPORTADORAS
}

Carla Diniz Naue ${ }^{1}$

Nathalia Berger Werlang ${ }^{2}$

Inocencia Dalbosco ${ }^{3}$

${ }^{1}$ Centro Universitário FAI - UCEFF / Centro Universitário FAI - UCEFF

${ }^{2}$ Centro Universitário FAI - UCEFF

${ }^{3}$ Universidade do Oeste de Santa Catarina (UNOESC) 


\section{ANÁLISE DA ESTRATÉGIA INICIAL DE INTERNACIONALIZAÇÃO: ESTUDO MULTICASOS DE EMPRESAS EXPORTADORAS}

Resumo: A internacionalização está vinculada a ampliação de conhecimento e abertura de mercado, assim sendo o presente trabalho teve por objetivo identificar os fatores relacionados a estratégia de exportação. Para alcançar o objetivo proposto foi desenvolvido um estudo múltiplo de casos, onde gestores e proprietários de três organizações foram questionados sobre as particularidades de cada empresa no processo de expansão. Quanto aos resultados percebidos observou-se que o motivo central pela busca da comercialização internacional esteve vinculado aos ganhos financeiros, além da expansão de clientes e redução da dependência do mercado interno. A realização de alianças estratégicas, o network e o auxílio das políticas públicas no fomento da expansão das empresas brasileiras também compunham parte da motivação. Com relação a exportação, mapeou-se que é a estratégia mais comumente utilizada e a escolha está vinculada ao baixo investimento financeiro e redução de tempo para efetivação da venda ao mercado externo.

Palavras-chave: Internacionalização. Exportação. Aliança estratégica. Network. 


\section{Introdução}

Conforme Zen et al., (2013) as transformações sistêmicas das últimas décadas, advindas da globalização e do incentivo nas transações comerciais, relacionam a internacionalização ao aumento de oportunidades de expansão e incremento na concorrência local. A inserção das organizações e produtos estrangeiros aumenta a instabilidade nas condições de mercado interno, fator este responsável pela demanda de participação no mercado global, a fim de reduzir a dependência do mercado interno.

Em âmbito global, a aceleração da competitividade instiga a adoção de ferramentas inovadoras de gestão, para melhor interface dos novos mercados consumidores. De acordo com Mota (2007), a alteração no gerenciamento das organizações interfere em todas as esferas, haja vista que o ambiente altamente competitivo impulsiona as mesmas a adquirir certificados que comprovem a superioridade dos quesitos qualidade e eficiência dos seus processos produtivos.

Por conta disso, entende- se que a internacionalização compõe a parte mais relevante do processo estratégico, e não se resume estritamente a realizar vendas casuais a outros países, e sim à capacidade de desenvolver mudanças no escopo da atuação da empresa, por meio da ampliação de ideias de negócios e da organização interna. A forma utilizada pelas companhias para iniciar suas operações em mercados internacionais pode ocorrer por diversos meios, tais como operações de exportação, importação, franquias, alianças estratégicas, joint ventures, investimento externo direto (MELIN, 1992).

A expansão comercial, através da internacionalização, é um desafio crescente para as empresas brasileiras, principalmente no que tange aos setores de vasta competitividade no mercado interno. A inserção no mercado externo, neste caso, é uma escolha estratégica, vinculada a captação de novos clientes, incremento do mix de produção e afirmação no mercado nacional (ZEN et al., 2013).

Com relação a estratégia de exportação, Kovacs, Moraes e Oliveira (2008) salientam que a atividade possibilita o acesso a novos mercados, o aumento da eficácia dos processos produtivos e qualidade dos produtos, bem como o incremento financeiro.

Em reportagem em Julho de 2017 conduzida por Cristiana Indio do Brasil (repórter da Agência Brasil), o Ministro da Fazenda, Henrique Meirelles, salientou que a economia brasileira tem mantido o seu ritmo normal, fator este, decisivo para o acréscimo nos investimentos e na criação de empregos. Além disso, Meirelles destacou que algumas medidas estão sendo conduzidas, e que em breve serão anunciadas, entre elas a redução de $40 \%$ no tempo do processo brasileiro de importação e exportação.

Neste sentido conforme publicação do site da Apex Brasil em 2017, Cristiano Braga (gerente de exportação da Apex Brasil), relacionou a busca crescente pela inserção de PME's no mercado global não vincula-se somente à oportunlidade de abertura de novos mercados, mas também ao desenvolvimento de soluções inovadoras e sustentáveis à nível de grandes companhias. Fato comprovado na segunda edição do Projeto Inovação e Sustentabilidade nas Cadeias de Valor Global (ICV), conduzido pela Fundação Getúlio Vargas (FGV) em conjunto com a Agência Brasileira de Promoção de Exportações e Investimentos (APEX-BRASIL, 2017). No entanto, para conquistar o faturamento em moeda internacional, se faz necessário desenvolver estratégias a longo prazo que impactem fortemente na gestão organizacional. Além disso, a formação de equipes de venda especializadas e processos certificados para exigências internacionais são aspectos primordiais para sustentar os acordos comerciais a nível global. 
Diante do exposto, este estudo teve como objetivo identificar os fatores relevantes do processo de internacionalização de três Empresas do Oeste Catarinense. Para isso, realizou-se um estudo múltiplo de casos comparativo do processo de internacionalização através da exportação. A análise dos aspectos relacionados ao assunto possui valor ao contribuir no desenvolvimento teórico e prático, além do direcionamento de futuras pesquisas relacionadas às lacunas teóricas apresentadas acerca do tema.

Esta pesquisa justificou-se pela contribuição na construção do conhecimento acadêmico e prático do processo de internacionalização e das estratégias utilizadas pelas empresas analisadas. Além disso, o trabalho em questão, contribui social e cientificamente com a disseminação de aspectos considerados importantes para a estrutura e efetivação de negócios internacionais e ampliação de conhecimento acerca do tema.

\section{Referencial Teórico}

Com o intuito de inserir o leitor no processo de expansão de mercado serão apresentadas, a seguir, as duas principais teorias relacionadas ao tema. Visto que a internacionalização é formulada essencialmente sob às perspectivas econômica e comportamental. Nos subcapítulos seguintes serão descritos os principais conceitos das teorias: o Paradigma Eclético de Dunning e a Teoria Comportamental de Uppsala. Além disso, serão apresentados aspectos da exportação como a estratégia inicial no processo de internacionalização.

\subsection{Abordagens e estratégias de internacionalização}

A delimitação da forma de inserção de mercado externo está ligada a uma série de aspectos, dos quais cabem destacar a situação socioeconômica, cultural e política do local de destino, bem como a análise das capacidades e recursos de produção e disponibilidade para suprimento da demanda (MOTA, 2007).

Conforme Mariotto (2007), o referencial teórico acerca do tema é composto por esferas múltiplas, destacando que as questões políticas, econômicas, financeiras e psíquicas são partes integrantes do processo de internacionalização. Apesar do número crescente de estudos relacionados ao comércio exterior, e seu início ser datado de 1960, o tema negócios internacionais, do qual a internacionalização faz parte, ainda está em processo de definição e delimitação teórica.

As teorias clássicas de internacionalização foram desenvolvidas sob perspectivas variadas de diversos autores, porém resumidamente elas podem ser classificadas por meio de duas abordagens principais:

a) econômica: quando prevalecem as soluções racionais para as questões do processo de internacionalização, e o objetivo de iniciar o comércio está atrelado à maximização de indicadores econômicos e financeiros;

b) organizacional ou comportamental: o processo de internacionalização depende das percepções e comportamentos dos tomadores de decisão, neste sentido a escolha de destino está relacionada a redução dos riscos de incompatibilidade comercial (HILAL; HEMAIS, 2002)

Os estudos sobre a exportação como estratégia de internacionalização iniciaram com a análise das oportunidades e obstáculos do processo de expansão, em esfera mundial. Com isso, duas vertentes consolidaram-se ao englobar os diversos modelos até o momento desenvolvidos, sendo estes fundamentados na abordagem econômica e comportamental. As teorias que

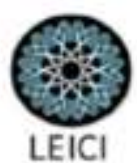


abordam os aspectos econômicos, são descritas baseadas em dados e informações concretos quanto à maximização de retorno financeiro através da expansão de mercado. Assim, entre os diversos modelos que compõem essa abordagem, destaca-se o Paradigma Eclético de Dunning (DAL-SOTO, ALVES E BULÉ, 2014).

Parafraseando Dunning (1988), o Paradigma Eclético apresentado em 1976 é um rascunho inicial da análise da produção internacional, construído para a identificação dos fatores econômicos influenciadores da iniciativa de implantação de processos produtivos, além do local de origem das organizações.

A delimitação de destino relaciona as vantagens de local, num viés econômico e monopolístico das organizações, sendo que as mudanças geográficas de mercados reduzem a dependência de mercado e aumentam a sustentação das operações. Neste contexto, a estratégia utilizada para iniciar o processo de internacionalização é particular e dependente dos recursos financeiros e capacidade produtiva de cada organização (DUNNING,1988).

O Paradigma Eclético de Dunning, através da visão "OLI", reúne características essenciais para obtenção de vantagem sobre o local de expansão. Com relação à sigla, cada letra representa uma propriedade específica de diferencial competitivo, contando que Ownership refere-se à propriedade, Location à localização e Internalization à internalização. De acordo com Caseiro (2013), para que uma organização possa efetuar a internacionalização com potencial e segurança competitiva é essencial que a mesma possua, ao menos, uma vantagem diferencial sobre os demais competidores.

As vantagens comparativas das organizações são compostas essencialmente pela tríplice "OLI". Em que se pese, a propriedade, se refere às especificidades da natureza ou nacionalidade da organização e aos ativos intangíveis (marcas e patentes). A localização abrange os aspectos estruturais, econômicos, financeiros e políticos do local. Quanto ao fator de internalização, que trata da capacidade de redução de perdas de mercado, através da absorção dos aspectos positivos dos locais com os quais a organização possui vínculo. O processo de disseminar as boas práticas por toda a cadeia aumenta significativamente a competitividade da organização (DUNNING, 1988).

Em contrapartida ao modelo puramente econômico de Dunning, a escola de Uppsala, conceituada por Johanson e Vahlne (1977), relaciona a internacionalização por uma abordagem comportamental, na qual o processo de expansão ocorre de forma gradual e incremental, sendo, em muitos casos reflexo do crescimento e saturação de atendimento ao mercado interno.

Os resultados da observação de quatro empresas suecas, feitas por Johanson e Wiedersheim-Paul (1975) identificaram que os aspectos motivadores para o início das operações no exterior possuíam relação com a proximidade geográfica e cultural dos locais. Além disso, observaram que as firmas entravam em novos mercados através da exportação, em função redução de riscos e baixo investimento financeiro. Para tanto, de acordo com Teixeira e Flores (2014), a primeira parte deste processo é composta pela venda direta, seguida pela exportação com auxílio de agentes comerciais e, por último, ocorrendo a aquisição de subsidiárias.

A experiência acadêmica feita por Johanson e Wiedersheim-Paul na Universidade de Uppsala, aborda a internacionalização como parte de um sistema mutável e complexo, visto que as organizações são formadas por fatores intangíveis e cumulativos, não é possível reduzir as estratégias á somente de natureza quantitativa (DAL-SOTO; ALVES; BULÉ, 2014).
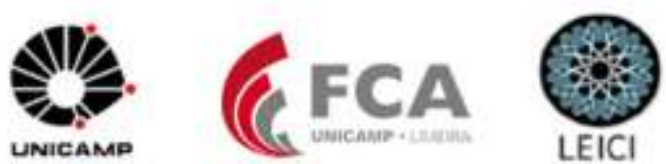
Neste sentido, o conhecimento do ambiente internacional acontece conforme as experiências entre destinos, e a limitação acerca do conhecimento de aspectos culturais, sociais e políticos se tornam um entrave na construção de parcerias. Desta forma, a preferência por destinos com maior proximidade psíquica ocorre em função da similaridade de processos já efetuados nacionalmente (JOHANSON; VAHLNE, 1977).

Caseiro (2013) preconiza que o conjunto de vantagens da internacionalização ocorre porque as empresas envolvidas complementam suas vantagens, incrementam o processo produtivo e reduzem as falhas por meio da incorporação de melhorias visualizadas nos processos fora do país de origem.

De acordo com as teorias supracitadas, a diversificação nas formas de ingresso em mercados externos se relaciona aos aspectos econômicos e produtivos de cada organização. As estratégias para posicionar a empresa além das fronteiras, não são totalmente distantes das utilizadas para absorção e ampliação do mercado nacional. No entanto, o processo de internacionalização engloba considerações amplas em termos de estratégias, comportamentos e economia se comparadas ao mesmo processo no próprio país (PETRY, et al., 1999).

Para efetivar o processo de expansão, é exigido que a organização possua o conhecimento das singularidades dos distintos vislumbrados, visto que, as estratégias a serem utilizadas para atingir o objetivo final são baseadas nos dados e informações sobre o local. Portanto, a delimitação da forma de ingresso deve ser estruturada de forma meticulosa, haja visto o risco e impacto financeiro e produtivo, caso insucesso de operação (MOTA, 2007).

Em função da exportação ser usualmente considerada a maneira mais rápida de efetivar negociações com menor investimento financeiro, é normalmente a estratégia utilizada para iniciar a internacionalização, para tanto, o presente trabalho irá abordar a seguir os principais constructos sobre tema.

\subsection{Exportação}

A troca de produtos específicos entre locais distintos retrata a forma mais antiga de efetuar relações comerciais entre países. Com relação a venda de mercadorias, Mariotto (2007) destaca que a exportação reduz os impactos caso não seja efetiva a transação comercial.

O baixo investimento, nessa forma de comércio, se deve ao fato de abster a organização de investimento estrutural no local de destino para a efetivar a comercialização, e por isso, é usualmente escolhida pelas organizações para iniciar a internacionalização (HITT, 2015).

A exportação, conforme o manual do Ministério de Relações Exteriores (2011), constitui o faturamento individual entre produtor e importador e, por isso, exige que a empresa possua conhecimento do processo como um todo, incluindo a documentação exigida, acordos comerciais, padrões de produção, logística de entrega, entre outros.

Os termos internacionais de Comércio "Incoterms", servem para definir, dentro da estrutura do contrato de compra e venda internacional, os direitos e obrigações recíprocos do exportador e importador. Além de estabelece o conjunto padronizado de definições e regras, como por exemplo: onde o exportador deve entregar a mercadoria, quem paga o frete, quem é o responsável pela contratação do seguro (MINISTÉRIO DAS RELAÇÕES, 2011).

Para a obtenção das informações relacionadas ao processo de exportação, normalmente são utilizados agentes especializados, através da contratação de representantes comerciais. A

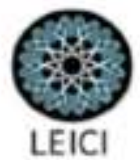


utilização de mão de obra especializada, neste caso, reduz possíveis gafes decorrentes da distância cultural e psíquica entre local de origem e destino (NETO; ALMEIDA, 2007).

Apesar do incremento de custo para à contratação de agentes especializados na efetivação da exportação, a estratégia em questão continua a ser considerada como a forma mais barata e menos arriscada de iniciar a internacionalização. Portanto, de acordo com Mota (2007), a exportação permite o acesso rápido ao mercado a um baixo custo operacional.

\subsection{Pesquisas recentes sobre exportação}

Com base nos dados acima descritos, onde é perceptível o impacto da exportação na internacionalização e participação das empresas brasileiras na economia global. Vincula-se o incremento crescente de autores envolvidos na construção de pesquisas referentes ao tema. Desta forma, foram identificadas e apresentadas a seguir as considerações dos estudos mais recentes sobre o tema.

De acordo com a pesquisa descritiva, documental e qualitativa de Pereira e Gomes (2017), com foco em quatro indústrias farmacêuticas consideradas multinacionais, onde se pode concluir que as estratégias desenvolvidas pelas organizações, no processo de internacionalização, aproximam-se das mais comumente utilizadas. Apesar das alterações constantes dos cenários, a internacionalização anda sob a ótica de dois modelos: o econômico (Paradigma Eclético de Dunning) e o comportamental (Escola de Upssala). Os resultados obtidos pelos pesquisadores sugerem que, neste caso, não houve a sofisticação do processo, pois as organizações seguiram basicamente as indicações prescritas pela literatura.

Contrastando a linearidade no processo de internacionalização descrita por Pereira e Gomes (2017), Nunes e Lequain (2016) constataram que a identificação dos mercados alvo é complexa, pois neste caso os gestores saem do seu "habitat" natural. Além disso, os quatro métodos de seleção de mercado, utilizados na pesquisa, não se aplicam à realidade das PME's. Visto que, a quantidade de informações, e a restrição no tempo para interpretação das mesmas, não converge com a realidade das organizações.

Com relação à análise dos aspectos financeiros, Rodrigues e Sordi (2016) objetivaram compreender a participação dos bancos nas redes de relacionamento influenciadores na internacionalização. De acordo com os autores, os bancos brasileiros poderiam desempenhar um papel mais significativo junto as organizações, por meio de serviços de consultoria, cursos e formas de extensão das parcerias internacionais.

Convergindo com a importância da solidificação das empresas, em âmbito internacional, em 05 de Outubro de 2016 o Presidente da República publicou o decreto $\mathrm{n}^{\circ} 8.870$ no site do Ministério de Comércio Internacional, sobre um procedimento simplificado de exportação para as Empresas optantes pelo Simples Nacional. O programa visa transferir para os operadores logísticos cadastrados junto à Receita Federal a responsabilidade por todo o processo de exportação, reduzindo a burocracia exigida nas operações de Comércio Exterior no Brasil.

Há, portanto, determinado consenso na academia quanto à importância da exportação no processo de internacionalização, por ser corriqueira e de menor investimento. Apesar de o tema apresentar uma lacuna perceptível entre teoria e a prática, observa-se que os conceitos atrelados a este estão cada mais presentes nas produções acadêmicas e visivelmente mais voltados à análise da prática para estruturação das partes.

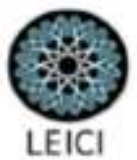




\section{Metodologia da Pesquisa}

Dada a natureza do problema abordado e em função deste estudo não se propor a testar hipóteses e sim, refinar a aplicabilidade das teorias da internacionalização na prática da expansão de mercado das organizações, optou-se pela realização de um estudo de natureza qualitativa.

A pesquisa qualitativa considera todos os fatores de influência na obtenção de informações, desde a tenacidade e pausa da fala ao silêncio. O que, conforme Rampazzo e Corrêa (2008), deve ser levado como referência para a realização de análises e interpretações das informações obtidas.

O estudo múltiplo de casos, segundo Yin (2010), possibilita a análise em diversas situações, visto que o mesmo tem por objetivo auxiliar na compreensão de fenômenos individuais relacionados a pesquisa. As técnicas empregadas no presente estudo foram de cunho exploratório, descritivo e explicativo, e ocorreu através da coleta de dados primários e secundários (MARCONI; LAKATOS, 2010).

Para realização desse estudo, a amostra foi composta por três empresas da região Oeste Catarinense, ambas em processo de internacionalização. Apesar da diferença de ramos de atuação, todas possuem impacto em indicadores econômicos e sociais dos municípios em que estão instaladas.

Cabe destacar que este artigo em forma de estudo de caso foi submetido e aprovado pelo CEP (Comitê de Ética em Pesquisa), e está em obediência aos preceitos da resolução do Conselho Nacional de Saúde (196/96) e do Conselho Federal de Psicologia (16/2000), que incluem o sigilo quanto a identidade dos participantes e a livre aderência ao estudo.

A coleta dos dados primários ocorreu por meio de observação direta, a partir de visita aos locais de atividade, e entrevistas semiabertas com os proprietários e participantes do processo de expansão comercial. Para efetivar o presente trabalho, se utilizou o roteiro de entrevista proposto por Rosa (2006), que fundamenta seu método em entrevista guiada, com roteiro baseado nos objetivos e referenciais teóricos acerca da internacionalização.

$\mathrm{O}$ roteiro de entrevista, dividido em três seções, onde a primeira visou a análise total do processo de internacionalização, através das informações de motivações, dificuldades, delimitação de mercado, formas de entradas e parcerias. Na segunda etapa foram avaliados os impactos financeiros esperados após a expansão comercial, além das considerações específicas levantadas pelos participantes. E por último, foram abordadas as influências de políticas públicas, incentivos e entraves do setor público no processo de comercialização. As entrevistas foram realizadas pelos próprios pesquisadores e com a permissão dos participantes, puderam ser gravadas, sendo as respostas transcritas para a realização e interpretação das informações.

O método de análise utilizado nesse trabalho foi a de conteúdo, que segundo Bardin (2004), é um acumulado de técnicas para avaliação de comunicações, visando obter indicadores que permitam a geração de conhecimentos relativos às condições de produção/recepção dessas mensagens.

Para análise dos dados, estes foram separados em categorias para melhor mapeamento: a) motivações para internacionalização; b) escolha do mercado; c) estratégias de entrada em mercados estrangeiros; e) desafios e oportunidades do processo de internacionalização f) políticas públicas de incentivo a internacionalização.

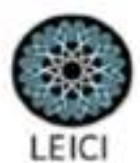




\section{Apresentação e discussão dos resultados}

Nesta pesquisa realizaram-se entrevistas com os proprietários e participantes do processo de internacionalização de três empresas da Região Oeste Catarinense, ambas através da estratégia de exportação. As organizações atuantes nos ramos alimentício e de vestuário foram selecionadas em função da proximidade geográfica, impacto socioeconômico e similaridade quanto a estratégia utilizada para expansão comercial.

Cabe ressaltar que todos os participantes deste estudo possuem conhecimento e experiência tanto no âmbito técnico e administrativo quanto estratégico, nas respectivas empresas. Sendo as entrevistas, neste caso, suficientes para um estudo com resultado satisfatório, visto que as respostas dos participantes fundamentaram a descrição dos fatores considerados relevantes no processo de internacionalização.

\subsection{Perfil da Amostra}

Para melhor caracterização dos perfis da amostra, são apresentadas, no Quadro 01, as características inerentes à cada organização.

Quadro 01: Dados de caracterização das organizações respondentes

\begin{tabular}{|l|l|l|l|}
\hline Variável avaliada & Empresa A & Empresa B & Empresa C \\
\hline Cidade em que se localiza & São Miguel do Oeste & São João do Oeste & Iporã \\
\hline Cargos dos respondentes & Proprietárias & Proprietário e Gerente & Proprietários \\
\hline Produtos exportados & Biquínis & Requeijão & Biscoitos \\
\hline Destino de exportação & Estados Unidos & Estados Unidos & Estados Unidos \\
\hline Tempo de atuação (anos) & 6 & 18 & 17 \\
\hline
\end{tabular}

Fonte: Dados da pesquisa

A empresa A atua no mercado têxtil de pijamas, lingeries e biquínis há 6 anos, sendo referência regional de qualidade e design inovador. A intenção de internacionalizar os negócios se deu por meio da seleção da organização em compor o time de negócios do Programa Exporta SC, conduzido pelo SEBRAE em parceria com a Apex, em janeiro de 2015.

A organização B é um dos principais players do mercado lácteo brasileiro e com uma atuação de 18 anos, consolida-se como referência em inovação e produtos de qualidade. Com o foco na produção de itens de valor agregado, tem como fim garantir a visão diferenciada do cliente com relação aos seus produtos. A intensão de exportar começou através de um insight do proprietário em 2016 ao visitar um mercado no local de destino (EUA).

A empresa $\mathrm{C}$ está presente no mercado regional há cerca de 17 anos, iniciou e mantem as atividades como negócio familiar. Atuante no de farináceos industrializados, o interesse em fazer parte do mercado internacional, iniciou através da seleção para o Programa Exporta SC, em janeiro de 2015 .

\subsection{Motivações para internacionalização.}

Com relação aos fatores que motivaram as empresas no processo de expansão de mercado, houveram semelhanças entre as respostas das organizações $\mathrm{A}$ e $\mathrm{C}$, visto que ambas participaram do programa Exporta SC, desenvolvido pelo SEBRAE em 2015. "Pensávamos não estarmos aptos para a exportação, mas ao saber que a empresa compunha as 50 selecionadas

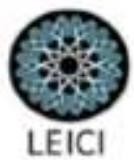


para o programa, tivemos a motivação para estruturar o que faltava no processo, para a produção dos itens exportáveis que fariam parte do nosso mix" (Empresa C).

Em contrapartida, no caso da organização B, o fator motivacional foi o insight do proprietário durante uma viagem ao exterior, onde o empresário percebeu o potencial de venda do requeijão, reconhecido no local de destino como produto genuinamente brasileiro, e com uma proporção interessante de consumidores brasileiros.

Apesar da dispersão entre as motivações iniciais, cabe ressaltar que em ambas as organizações o ganho financeiro, resultado dos incentivos governamentais, destacaram-se como base para efetivação do plano de exportação, visto que todos destacaram a redução da carga tributária para compra da matéria prima importada e incremento no preço de venda do produto final. Em consenso a isso, Dunning (1988), abordou no Paradigma Eclético que as motivações para venda ao mercado externo ocorrem em virtude dos ganhos financeiros, eficiência e recursos produtivos, bem como o acesso a novos mercados.

Neste sentido, a afirmativa do proprietário da Empresa B, em que se pese a motivação "vender para fora do Brasil, [...] um produto com a mesma qualidade e com um ganho superior, em função da redução da carga tributária, impactou na decisão de internacionalizar os negócios", convergente com a indicação de Romero (2006), que salienta que o principal motivo para a comercialização internacional está atrelado ao incremento da lucratividade.

Com relação as motivações, Douglas e Craig (1989) asseveram ainda que existem oito fatores principais para a inserção ao mercado externo, dentre eles: o atendimento a consumidores domésticos nos mercados externos, a busca de novas oportunidades e os incentivos governamentais.

\subsection{A escolha de mercados}

De acordo com Fleury (1981), a decisão sobre o destino dos produtos ocorre com base na existência de um contato entre importador e exportador, informações sobre mercado, análise comparativa da concorrência local e proximidade psíquica.

A questão relacionada à escolha de mercados para efetivação da exportação, bem como o conhecimento necessário para efetuar as transações comerciais foram citadas singularmente entre os participantes das empresas $\mathrm{A}$ e $\mathrm{C}$, visto que ambas participaram do mesmo programa e receberam as mesmas designações quanto ao destino.

"Tivemos uma mistura de sensações quanto ao rumo da nossa empresa nas primeiras etapas do programa. [...], só teríamos certeza da escolha em participar ao fechar o primeiro container para a Flórida" (Empresa A).

De acordo com os participantes da empresa C, "a pesquisa de mercado, com as delimitações sobre destino [...] foi conduzida pelo Sebrae, nós podíamos opinar sobre as questões produtivas, [...] ainda assim, acredito que o destino não poderia ser mais competitivo".

A semelhança de respostas neste estudo se deve à proporção que a expansão comercial tem sobre as organizações, pois ambas contam com a capacidade produtiva e qualidade percebida dos seus produtos. Em que se pese, o crescimento organizacional e financeiro, proporcionado pela inserção no mercado externo é proporcional ao desafio dos gestores na eficiência dos seus processos nacionais (NUNES; LEQUAIN, 2016).

Ao analisar a fala do proprietário da empresa B, observa-se a importância da diversificação de rede de relacionamento para estruturação de negócios internacionais, "a

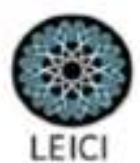


escolha pelos EUA como destino foi em função da receptividade local aos produtos brasileiros, em especial o requeijão [...], e a facilidade proposta na comercialização por intermédio de uma empresa no local de destino".

O papel desempenhado pelas redes de relacionamento "networking" tem sido comparado à estratégia descrita pelo modelo de Uppsala, vista a proximidade de papeis desempenhados entre parceiros de negócios na perspectiva organizacional (HEMAIS; HILAL, 2002).

\subsection{Estratégias de entrada em mercados estrangeiros}

As operações internacionais podem ser efetuadas por diversos caminhos, tais como a exportação (direta ou indireta), instalação de subsidiarias e construção de alianças estratégicas. A forma de entrada precisa ser feita de forma concisa e cautelosa, baseada em informações confiáveis sobre o destino e suas particularidades. Com isso os participantes foram questionados quanto as escolhas feitas pelas organizações.

De acordo com a sócia proprietária da Empresa C "O Sebrae delimitou o modo de entrada através exportação, com base em pesquisa [...]. Por isso, uma trading foi escolhida para a distribuição dos nossos produtos nos EUA". A facilidade proposta por empresas que são concebidas à nível global, contrária a realidade da maioria das organizações brasileiras, explicam porque as empresas iniciam as atividades internacionais através da exportação e em parceria com as organizações do destino (RIBEIRO, 2012).

Além disso a facilidade proposta pela construção de parcerias está presente na afirmativa do proprietário da empresa B, "a parceria com a empresa do local de destino reduziu os riscos de irregularidades e inconformidades de documentação, além de facilitar a inserção e distribuição dos produtos no território".

Em consonância a isso, Hitt (2015) afirma que a exportação indireta é costumeiramente utilizada na primeira experiência de venda ao mercado externo, e ocorre por intermédio de comercial exportadora, trading exportadora ou agente de exportação para efetivação dos negócios.

4.5 Desafios e oportunidades do processo de internacionalização.

Em função de as empresas $\mathrm{A}$ e $\mathrm{C}$ não terem efetivado nenhuma exportação até o momento da entrega da pesquisa, os obstáculos relatados são relacionados à burocracia envolta para atendimento das exigências legais dos EUA. Apesar de o programa ter iniciado em 2015, com base na receptividade de mercado aos produtos brasileiros e com o intuito de efetivar a venda em no máximo um ano, houveram restrições quanto ao registro da marca e custos de manutenção do local de armazenagem dos produtos.

"Exportar é muito fácil, se eu quiser, posso começar em três meses, porém isso pode custar muito caro e por isso nós optamos por usar nosso nome, o que aumenta os custos e o tempo para efetuar a venda" (Empresa C)

Conforme Rosa (2006), as barreiras relacionadas às exigências de entrada são geralmente de âmbito tarifário, variação cambial, fatores culturais e psíquicos. Para a redução dessas diferenças, cabe à organização buscar a parceria com empresas que atuam no mercadoalvo, a fim de facilitar conhecimento e buscar as redes de relacionamento.

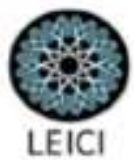


Em consonância a isso, foram relatadas pelo proprietário da empresa $\mathrm{B}$, as questões de atendimento às exigências sanitárias para entregar a produção no destino, "O Brasil tem um problema grave no sentido de legislação, [...], tivemos a perda de produto em função de preenchimento errado de documentação para certificação, [...]o entendimento do fiscal era diferente, há mudanças constantes de exigências sanitárias".

A segunda seção de entrevista fundamentou a análise nos impactos financeiros da venda ao exterior. Os questionamentos deste bloco basearam-se no aumento de desempenho, nos índices de rentabilidade e resultados monetários alcançados quando comparadas as expectativas.

Com relação a essa etapa, não foi possível a mensuração de dados concretos, em função das empresas $\mathrm{A}$ e $\mathrm{C}$ não terem efetivado nenhuma venda. A empresa $\mathrm{B}$, enviou a primeira carga há menos de um semestre e em volume insignificante para a questão financeira $(0,4 \%)$ dificultando, dessa forma, o mapeamento dos impactos monetários envoltos na efetivação da exportação. Para tanto, o foco da entrevista foi direcionado para a compreensão das expectativas relacionadas aos ganhos financeiros da exportação.

Corroborando, de acordo com o manual do Ministério de Relações Exteriores (2011) os produtos exportados são isentos do IPI, e não ocorre a incidência do ICMS. Além disso, a organização beneficia-se também dos créditos fiscais incidentes sobre os insumos utilizados no processo produtivo.

Neste caso, as expectativas com as vendas para o mercado exterior condizem com as motivações para a inserção em esfera global, visto a redução de impostos na compra da matéria prima e impacto positivo da redução tributária no preço de final de venda.

\subsection{Políticas públicas de incentivo a internacionalização.}

Durante a pesquisa, foram constatados incentivos governamentais vinculados somente a redução da carga tributária. De acordo com o proprietário da empresa B "no Brasil ainda estamos distantes de nascermos como empresas globalizadas, e a única vantagem em tentar expandir é em função da redução de impostos para venda, o governo ajudaria muito se não mudasse as regras e intuísse normas frequentemente".

No caso das empresas $\mathrm{A}$ e $\mathrm{C}$, no entanto, houve à utilização do programa Exporta SC, conduzido pelo SEBRAE em parceria com a Apex, para o desenvolvimento do plano de negócios internacionais e as adequações para efetuar a venda ao mercado externo. Além disso, houve a parceria com a Apex, para a participação de eventos internacionais e demonstração dos produtos produzidos, "nós fomos ao Uruguai expor pela Apex em 2016 no Uruguai [...], sendo que o maior custo ficou por parte da agencia, e fomos sendo convidados a participar de uma feira na Argentina em novembro de 2017" (Empresa C)

Quanto às questões voltadas ao que poderia ser feito por parte do governo no desenvolvimento de negócios internacionais, a principal oportunidade foi em relação ao conhecimento. "Ainda não temos um manual claro e conciso sobre todas as peculiaridades relacionadas ao comércio exterior [...] o governo precisa disseminar o desejo pela expansão e conhecimento dos ganhos financeiros e organizacionais internacionalização" (Empresa B)

Conforme Menezes (2012), o número de organizações presentes no mercado internacional ainda é baixo, apesar da relevância da internacionalização na competitividade à

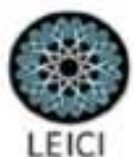


nível nacional, no que se pese a falta de conhecimento acerca do processo, é reconhecida na maioria das organizações, em especial as PME's.

A falta de instrução quanto à operacionalização da exportação como estratégia de internacionalização fica evidente na fala do proprietário da empresa B "Nós não temos condições de criar um setor voltado somente a internacionalização, pois isso incutiria em incremento de custos, além disso, acredito que na região não teríamos sequer a mão de obra especializada no assunto".

Em consonância aos incentivos do governo brasileiro, Mendes (2012) descreve que os incentivos ocorrem desde meados do século XX, e são voltados principalmente para o fomento da competitividade das empresas no mercado interno e externo, dentre esses podem-se citar as linhas de financiamento ofertadas pelo BNDES e a atuação da Apex no sentido de estudo estratégico de negócios.

Para tanto, após a realização da pesquisa e com base nas informações nela obtidas, as autoras envolvidas no estudo sugerem um framework do processo de internacionalização através da exportação.

\subsection{Proposição de framework de internacionalização}

A partir dos casos observados, verificou-se que o processo de internacionalização é motivado tanto pela teoria comportamental, quanto pela econômica. Sob a perspectiva comportamental, destacam-se os aspectos da proximidade psíquica, por meio de hábitos de consumo similares entre organização e clientes potenciais, e sob a ótica econômica, evidenciouse a vantagem de internalização das práticas observadas no destino também compunham parte dos fatores iniciais para construção do plano. A Figura 1 apresenta o Framework proposto a partir deste estudo.

Figura 1: Framework processo de internacionalização

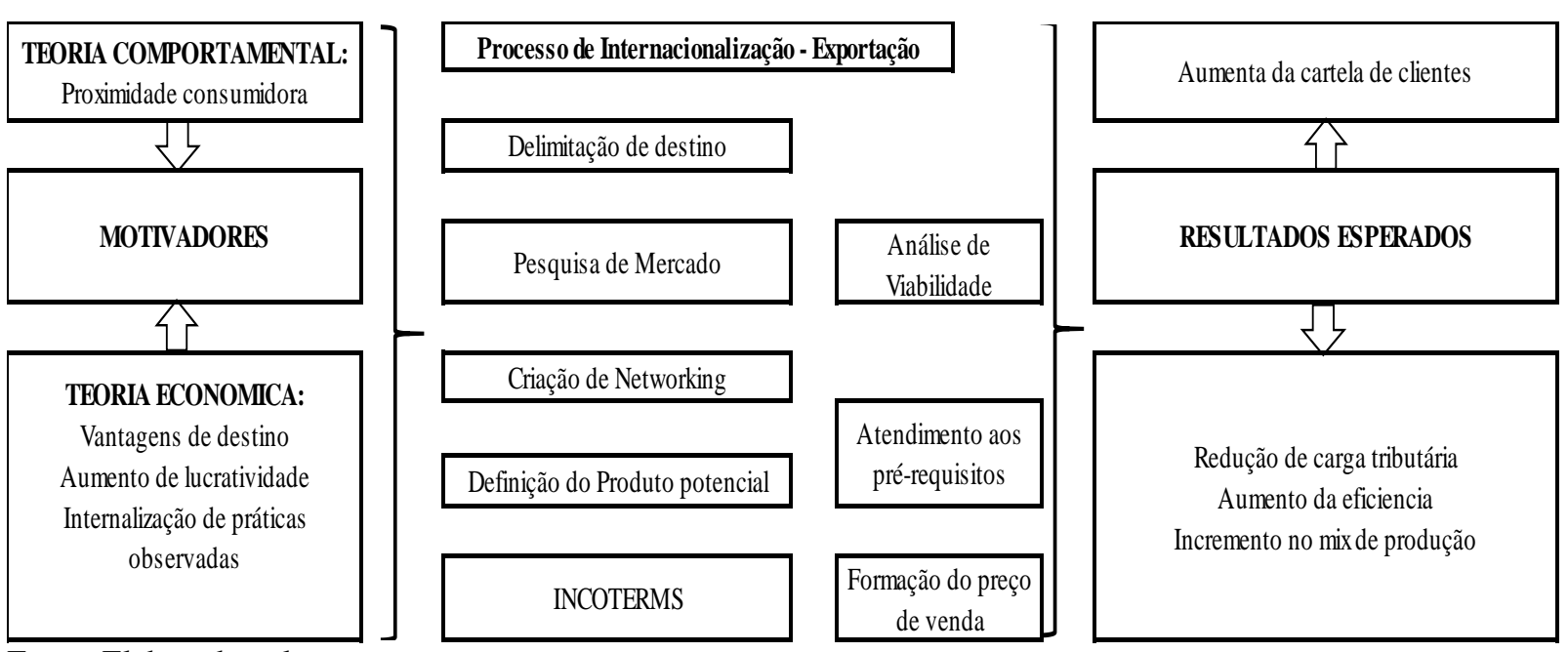

Fonte: Elaborado pelas autoras 
Ainda em relação a internacionalização, visualizou-se que a estratégia de exportação foi escolhida por todas as organizações, e que a mesma segue basicamente as etapas: escolha do local para venda, pesquisa de mercado e análise da viabilidade de negócios, parte esta estratégia e fundamental, pois nessa fase da estruturação do plano, são levantados os entraves e adequações necessárias para a efetivação de vendas.

As questões subsequentes de criação de redes de relacionamento, definição do produto, atendimento aos pré-requisitos, delimitação de incoterms e formação de preço de venda, são geralmente menos burocráticos, por serem de abrangência operacional.

Como parte final da análise, e em decorrência das motivações vinculadas a teoria comportamental, observou-se que ao iniciar o processo de internacionalização as organizações buscam pelo incremento na cartela de clientes e aumento da presença de marca no mercado interno. No entanto, a base financeira compôs com maior presença esta etapa, onde foram mapeadas a busca pela redução da carga tributária, o aumento da eficiência produtiva e incremento no mix de produção.

Após a construção de um modelo de etapas do processo de internacionalização, através da exportação são apresentadas as considerações, limitações e indicações de futuras pesquisas sobre o tema.

\section{Considerações finais}

O trabalho em questão buscou o estudo da exportação, como estratégia de internacionalização de três empresas situadas no Extremo Oeste Catarinense. Para alcançar o objetivo proposto foi desenvolvido um estudo de natureza descritiva, de abordagem qualitativa, por meio do estudo múltiplo de casos. As questões que compunham o roteiro de entrevista para verificação das variáveis investigadas, foram aplicadas em profundidade com os gestores e proprietários das organizações.

Ao analisar e sintetizar as alianças estratégicas realizadas com órgãos públicos e parceiros comerciais ficou perceptível o retrato das teorias de internacionalização. No entanto, não é possível delimitar proporção sobressaliente entre as duas linhas principais desse estudo. Pois ao mesmo tempo em que as organizações buscaram pelo destino com maior proximidade cultural e intelectual (Uppsala), houve também a questão das vantagens comparativas (Dunning).

A parte inicial deste artigo, procurou compreender as motivações que levaram as empresas a iniciar o processo de internacionalização. Onde se constatou que, o principal motivo é lucratividade, pois ao efetuar vendas ao mercado externo a carga tributária dos produtos é reduzida, maximizando a margem financeira da organização. Além disso, em consequência ao status de exportadora as organizações objetivaram aumentar a abrangência no mercado interno.

Acompanhando o processo, mapeou-se os métodos de entrada no mercado internacional, e no caso de todas as empresas, houve a utilização de tradings como organismos facilitadores entre fabricante e cliente, fato decorrente da construção de redes de relacionamento para efetuar a exportação.

Além disso, no que tange às alianças estratégicas e utilização de políticas públicas para processo de expansão, em todas as organizações desse estudo, houve o desenvolvimento de networking com parceiros nacionais e internacionais para viabilizar o processo. Mesmo que as empresas $\mathrm{A}$ e $\mathrm{C}$ não tenham efetuado uma venda ao mercado exterior, ficou evidente que os

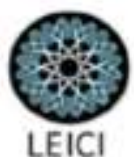


parceiros conhecidos no programa Exporta SC, tiveram participação na construção de alianças para o desenvolvimento de negócios, tanto na esfera nacional quanto internacional.

Com relação às políticas públicas para o desenvolvimento de internacionalização das empresas brasileiros, houve uma dispersão entre as respondentes. Pois, verificou-se que a Empresa B efetuou a pesquisa de mercado e venda dos seus produtos por processo individual e com capital próprio, enquanto as empresas $\mathrm{A}$ e $\mathrm{C}$ participaram de programa governamental para estruturação do plano de exportação. Neste sentido, quanto a importância do auxílio do governo para efetivação de negócios internacionais, a mesma é proporcional à ajuda recebida.

Ainda em relação a percepção dos proprietários no que tange a políticas públicas, ficou evidente é que a redução tributária dos produtos exportáveis é vista com bons olhos por ambos e considerada como a política pública mais importante de incentivo a internacionalização.

De acordo com os resultados propostos, o presente artigo teve seus objetivos alcançados, visto que mapeou a relação da estratégia de exportação nos processos de internacionalização mesmo que os ramos de atuação foram diferentes. Compete o destaque que o estudo de caso teve limitações, vinculadas à falta de informações dos impactos financeiros proporcionados pela venda ao mercado externo. E em relação a futuras pesquisas, sugere-se abarcar estudos relacionados a empresas da Região Oeste que possuem o processo concretizado de exportação, além da busca pela utilização de outras estratégias de internacionalização.

\section{Referências}

APEX-BRASIL.GVCES E Apex Brasil Trazem Resultados Do ICV Global 2017. Disponível em: www.apexbrasil.com.br. Acesso em: 19 agosto 2017.

BARDIN, Laurence. Análise de conteúdo. São Paulo: Edições 70, 2011.

BRASIL. Ministério das Relações Exteriores. Divisão de Programas de Promoção Comercial. Exportação Passo a Passo / Ministério das Relações Exteriores. - Brasília: MRE, 2011.

CASEIRO, Luiz C. Z. Novas estratégias de internacionalização de empresa brasileiras: expansão geográfica, determinantes e alternativas de política industrial. Dissertação de Mestrado da Faculdade de Filosofia, Letras e Ciências Humanas. Universidade de São Paulo, 2013.

CORRÊA, Fernanda Z. M.; RAMPAZZO, Sônia E. Desmistificando a metodologia científica: um guia prático de produção de trabalhos acadêmicos. Erechim: Habilis, 2008.

DAL-SOTO, Fábio ; ALVES, Juliano N.; BULÉ, Anieli E. Análise Do Processo De Internacionalização Do Modelo De Uppsala: Caminhos Para As Empresa Brasileiras. Revista ESTUDO \& DEBATE, Lajeado, v. 21, n. 1, p. 179-199, 2014.,

DOUGLAS, S. P.; CRAIG, C. S. Evolution of global marketing strategy: scale, scole and synergy.Columbia Journal of World Business. p. 47-59, fall, 1989. 
DUNNING, John $\mathrm{H}$. The eclectic paradigm of international production: a restatement and some possible extensions. Journal of International Business Studies, 1988.

FLEURY, P. F.; MEIRA, R. A.; SCHMIDT, A. M. R. A decisão de exportar e a escolha de mercados de exportação: dos aspectos conceituais às práticas gerenciais nas empresa brasileiras produtoras de manufaturados. Rev. adm. empres. 1981, v.21, n.3, pp. 7-13

HILAL, A.; HEMAIS, C. A. Da escola de Uppsala à escola Nórdica de Negócios Internacionais: uma revisão analítica. In: ENCONTRO NACIONAL DOS PROGRAMAS DE 14 PÓS-GRADUAÇÃO EM ADMINISTRAÇÃO, 20, 2001, Campinas. Anais... Rio de Janeiro, ANPAD, 2001.

HITT, Michael A.;HOSKISSON, Robert E.;IRELAND, R. Duane. Administração estratégica. Edição: 3.ed.. ed.: São Paulo: Cengage Learning, 2015

JOHANSON, J.; WIEDERSHEIM-PAUL, F. The internationalization of the firm - Four swedish cases. The Journal of Management Studies, p. 305-322, 1975.

JOHANSON,Jan; VAHLNE, Jan E. The internationalization process of the firm - a model of knowledge development and increasing foreign market commitments. Journal of International Business Studies, 1977.

KOVACS, Erica P., MORAES, Walter F. A. de; OLIVEIRA, Brigitte R. B. de. Redefinindo Conceitos: Um Ensaio Teórico Sobre Os Conceitos-Chave Das Teorias De Internacionalização. Revista de Gestão USP, São Paulo, v. 14, n. especial, p. 17-29, 2007

MARIOTTO, Fábio L. Estratégia internacional da empresa. São Paulo: Thomson Learning, 2007.

MELIN, L. Internationalization as a Strategy Process. Strategic Management. Journal, v. 13, n. S2, p. 99-118, 1992.

MENEZES, N. B. A Política Governamental Brasileira de Incentivo à Internacionalização de Empresa (1997-2005). Seminário Brasileiro de estudos estratégicos internacionais SEBREEI. Integração Regional e Cooperação Sul-Sul no Século XXI. Porto Alegre, 2012.

MOTA, Roberta B. Decisões Estratégicas no Processo de Internacionalização de Empresa: "Forma de Entrada" e "Seleção de Mercado". II Encontro de Estudos em Estratégia ANPAD, São Paulo 09 a 11 de Maio, 2007.

NETO, Alfredo J. M.; ALMEIDA, Fernando C. de. Os Condicionantes Do Comportamento Exportador Da Indústria Calçadista Francana. Revista REAd - Edição Especial 58, Vol 13, $\mathrm{N}^{\circ} 4$, dezembro de 2007. 
PEREIRA, A. J. P.; GOMES, J. S. Um Estudo das Estratégias de Internacionalização das Indústrias Farmacêuticas Brasileiras. Revista de Contabilidade e Organizações, v. 11, n. 29, p. 68-79, 2017.

PETRY, Jonas F.; BRIZOLLA, Maria M. B.; HERCULANO, Harlan de A.; HEIN, Nelson. Influência da internacionalização das empresas brasileiras na criação de valor. Revista Eletrônica de Estratégia \& Negócios, 2014.

RODRIGUES, H., \& DE SORDI, J. O. (2016). Exportação da Micro e Pequena Empresa: Análise da Atuação dos Bancos. Revista ADM.MADE, 20(3), 22-42

ROMERO, T. Dificuldades e atrativos presentes na exportação. Inovação Uniemp. 2006, vol.2, n.5, pp. 20-21. ISSN 1808-2394.

ROSA, Patrícia R.. Internacionalização da Empresa Marcopolo S. A.: Um estudo de caso. Tese (Mestrado em Administração) - Programa de de Pós Graduação em Administração, Universidade Federal do Rio Grande do Sul, Rio Grande do Sul, 2006.

TEIXEIRA, Ana P. P.; FLORES, F. S. O modelo de internacionalização de uppsala sob a ótica da visão baseada em recursos (RBV). Revista Eletrônica do Alto Vale do Itajaí REAVI, v. 3, n. 3, p. 001-012, set., 2014

YIN, Robert K. Estudo de caso: Planejamento e métodos. $4^{\text {a }}$ ed. Porto Alegre: Bookmann, 2010.

ZEN, A. C.; DALMORO, M.; FENSTERSEIFER, J. E.; WEGNER, D. Desenvolvimento de recursos em redes Inter organizacionais e o processo de internacionalização: o caso Wines of Brasil. Revista Ibero-Americana de Estratégia, v. 12, n. 1, p. 107-130, 2013. 